\title{
Median Nerve Injury from the Eye of an Artist: Gladiators
}

\author{
Tayfun HAKAN \\ Istanbul Okan University, Vocational School of Health Services, Division of Operating Room Services, Istanbul, Turkey \\ Corresponding author: Tayfun HAKAN tayfunhakan@yahoo.com
}

\section{ABSTRACT}

Artists use their work to help us understand the universe. With their creations, we can rest our souls, find some solutions to problems, and even explore new dimensions. A $19^{\text {th }}$-century artist, Gérôme, has depicted a gesture used to ask for mercy as a benediction sign in two of his works of art dealing with gladiatorial fighting. A warrior defeated in a gladiator combat is well known to ask for mercy with the extended index finger and fist. A benediction gesture by a gladiator after combat could be due to an acute nerve injury. At the sources that inspired the artist, the mercy gesture may have evolved into the benediction sign for an unknown reason. It is probable that a warrior cannot accurately form the mercy gesture following a peripheral nerve injury during combat. While his index finger was extended, the other fingers could not flex in the strict sense of making a fist due to traumatic median nerve injury.

KEYWORDS: Art, Benediction sign, Gladiator, Hand deformity, Median nerve, Medicine, Nerve injury

\section{INTRODUCTION}

A rt is an act of expression of how we perceive the universe, and painting and sculpture are the most important examples of visual art. Archeological studies show that painting and sculpture began with the history of humanity. History can be traced through visual symbols like sculpture and cave paintings, and it has developed with verbal arts such as mythology, poetry, and song. Later, art became a science through the invention of writing.

People have expressed their observations and emotions with art, and that expression has played an active role in the formation of history. The examination of historical artwork provides abundant information about society such as technological developments, life styles, and ways of thinking. Contemporary science provides the opportunity to study this art from the perspective of medicine.

In this article, a neurosurgeon discusses the perception of an artist through an event that occurred 19 centuries ago.

\section{GLADIATORS}

The meaning of the word gladiator is swordsman. It comes from gladius in Latin that means sword. Gladiators were professional combatants who lived in ancient Rome (6).
Typically, they were tasked with entertainment of an audience, and they participated in violent confrontations with other gladiators, wild animals, and condemned criminals. For the ancient people of Etruria, Italy; gladiators originally performed at Etruscan funerals with the intent to give a dead man armed attendants in the next world.

Prisoners of war, slaves, and condemned offenders were the main source of the gladiator population (11). There were mainly two kinds of gladiators. Ad gladium contestants fought in the arena without any prior training, and ad ludum participants received appropriate training in gladiator schools. The first type of gladiator was subjected to the rules of combat that meant certain death; however, the second type of fighters could ultimately achieve freedom after proving their worth in the course of the fight. Another less common group was the volunteer or "hobby" gladiators and included individuals such as citizens, senators, noblemen, and even emperors (11).

Jean-Léon Gérôme was a prominent French painter, sculptor, and teacher who lived from 1824-1904 (7). The sculpture, "Les Gladiateurs," was his first work, and it was shown to the public at the Exposition Universelle of 1878 . This $50 \mathrm{~cm}$ tall bronze sculpture is currently on display in an art museum, Ny Carlsberg Glyptotekis, in Copenhagen, Denmark (5).

Tayfun HAKAN (D) : 0000-0003-1444-7076 
Another sculpture called "Gérôme Executing the Gladiators" (a monument to Gérôme) was created by Aimé Morot, sonin-law of Gérôme, by request of the French government in 1909 (Figure 1) (8). This sculpture was a bronze casting, and the casting procedure was completed by A.A. Hebrard. In this piece, Gérôme was pictured sculpting "Les Gladiateurs". The theme of these sculptures was based on one of his paintings, "Pollice Verso" (1872) (Figure 2). "Pollice Verso" is an oil canvas and is located at the Phoenix Art Museum in Arizona, United States. This painting was deemed a chef d'oeuvre or masterpiece by an important and famous artist, Émile
Bergerat (3). The term pollice verso was used in the context of gladiatorial combat and meant with a turned thumb, which was a Latin phrase referring to the hand gesture used by Ancient Roman crowds to pass judgment on a defeated gladiator.

Although the gesture of the turned thumb is the main theme of both of these works of art, there is another gesture that requires our attention: the right hand of the defeated gladiator in the gesture pugnare ad digitum. This was when the gladiator raised his hand and fingers to stop the fight and request mercy or a reprieve. In the University of Chicago's Encyclopedia
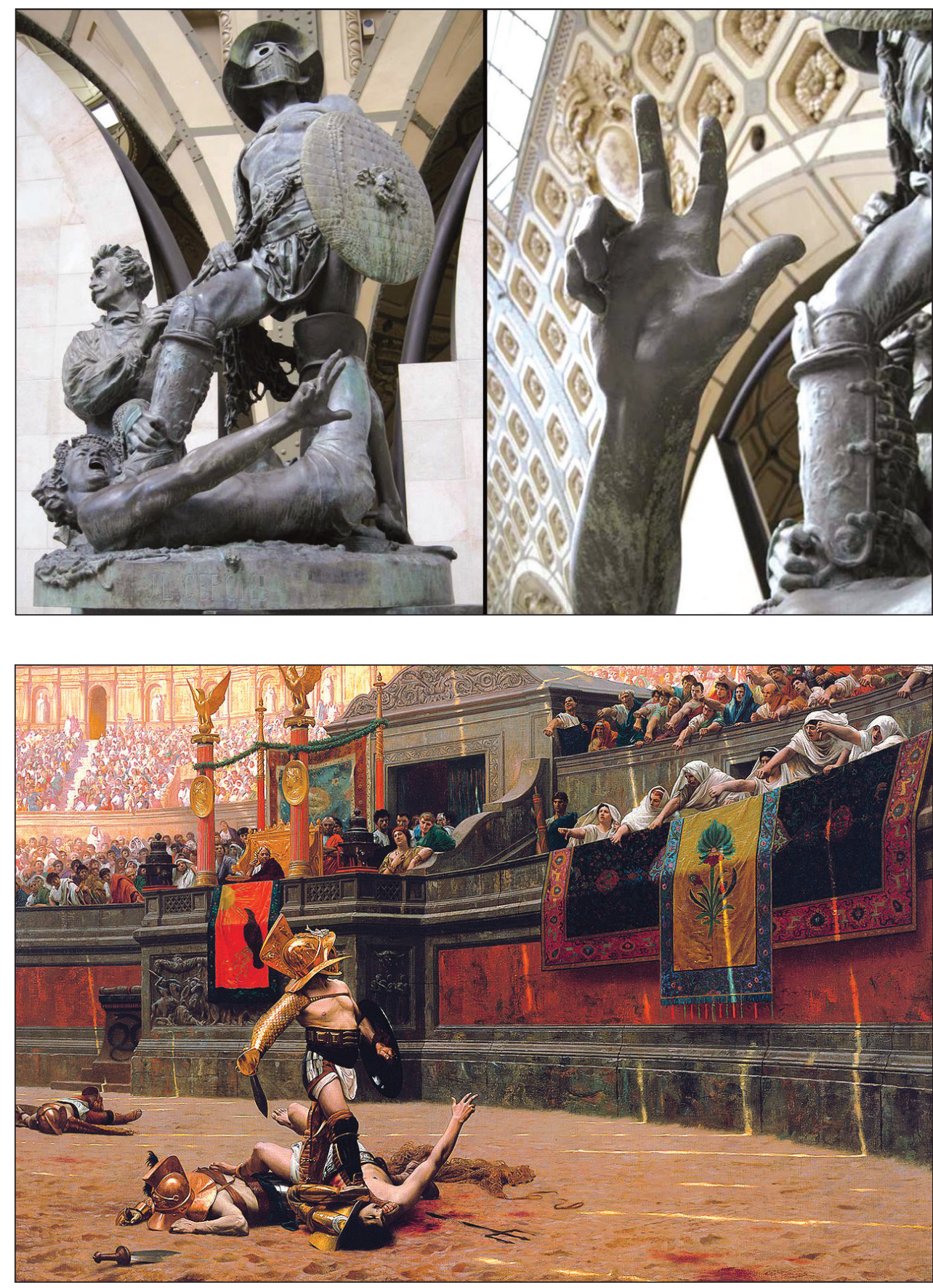

Figure 1: "Gérôme Executing the Gladiators" (monument to Gérôme). Bronze statue of a gladiator holding his foot on his victim (Left). Victim's hand is show the benediction sign (right). Artist: Aimé Morot. Musée d'Orsay, France. (Photo: Tayfun Hakan, M.D).
Figure 2: "Pollice Verso" 1872 painting by Jean-Léon Gérôme (Phoenix Art Museum, Phoenix, AZ, USA). https://en.wikipedia.org/wiki/ Pollice_verso\#/media/File:JeanLeon_Gerome_Pollice_Verso.jpg (accessed August 7, 2018). 
Romana (9), it is reported that a wounded gladiator would lay down his shield and raise his index finger, usually of the left hand, to plead for mercy, either from his opponent or from the judge. The decision of sparing a gladiator was often left to the editor-the manager of the combat- or emperor, but it was a custom to consider the opinions of the spectators. They could raise their fingers or yell, "spare him" (missium) by waving their handkerchiefs, or they could gesture with thumbs down (pollicem vertere) to signal their approval for the gladiator's death (10).

The gladiator's hand seems different from the descriptions in articles in oil paintings and sculptures $(9,10)$. Despite the sign of mercy being defined with the index figure, Gérôme portrayed a different gesture that became known as the hand of benediction. These artworks were imaginative; thus, whether this inaccurate gesture was intentional or mistaken will never be known because documentation was not provided. Gérôme never witnessed a live gladiator battle. He certainly must have read extensively about gladiator combat and hand gestures, but he created his artwork with the influence of intellectual accumulation. Perhaps his lack of knowledge about the exact Roman hand signals influenced his interpretation. If he had been able to attend a battle and painted just after witnessing a fight in the arena, it was not a mistake to speculate that he projected what he saw. In his notes, Gérôme explained his feelings and ideas about gladiators: "I had not at my disposition all the documents that I since have gathered together to work up the second. I had assembled all possible information that could contribute to its exactness. It has more of the accent of truth, and renders more clearly the brutal side of these Romans, by whom human life was counted as nothing" (3).

In this explanation, the first and second paintings Gérôme referenced are "Ave Caesar! Morituri te salutantis" and "Pollice Verso," respectively. Ave Caesar! Morituri te salutant is a well-known Latin phrase that is taken from an episode in Suetonius's Life of the Caesars (2nd century A.D.) (4). It means "Hail, Caesar! Those who are about to die salute you."

\section{MEDIAN NERVE}

The median nerve originates from the brachial plexus and receives branches from the lateral $[\mathrm{C} \mathrm{5}, 6,7]$ and medial $[\mathrm{C} 8, \mathrm{~T} 1]$ cords (16). It has no voluntary sensorial or motor branch but provides vascular branches in the upper arm. These branches usually innervate the brachial artery. At times, it may provide a branch to the pronator teres muscles that arise above the elbow in the distal arm. The median nerve innervates the muscles in three groups that are distal to the elbow. They are grouped as superficial (including pronator teres, flexor carpi radialis, and palmaris longus), intermediate (including the flexor digitorum superficialis muscle), and deep (including the lateral half of the flexor digitorum profundus, flexor pollicis longus, and pronator quadratus). The clinical manifestations of a median nerve lesion depend on the level of the lesion (14).

\section{BENEDICTION SIGN}

The benediction sign is a gesture of the wrist with three raised fingers in the hand. In explanations of the theologians, the three fingers extended together represent the "Holy Trinity", while the two bent fingers represent the duality of Jesus (2). In Greek culture, the benediction sign is when the thumb touches the tip of the ring finger as the index, middle, and little fingers are upright (15). In the Latin gesture, the thumb, index, and middle fingers are extended as the other two fingers are bent onto the palm of the hand.

In Ancient Roman culture, the benediction gesture was allegorically interpreted as power, authority, and divinity. It is clearly seen in the marble statue "Augustus of Prima Porta,"in which the emperor Augustus assumed the pose of an orator in addressing his troops (Figure 3).

The origin of the benediction sign has been a source of controversy, thought to be the result of either an injury to the median nerve or the ulnar nerve (2). The emerging hand posture is similar, regardless of whether it is a median or an ulnar nerve injury. Some authors stated that typical deficits that occur following injury to the median nerve in the upper arm cause the "benediction attitude" or "pope's blessing hand" $(12,14)$.

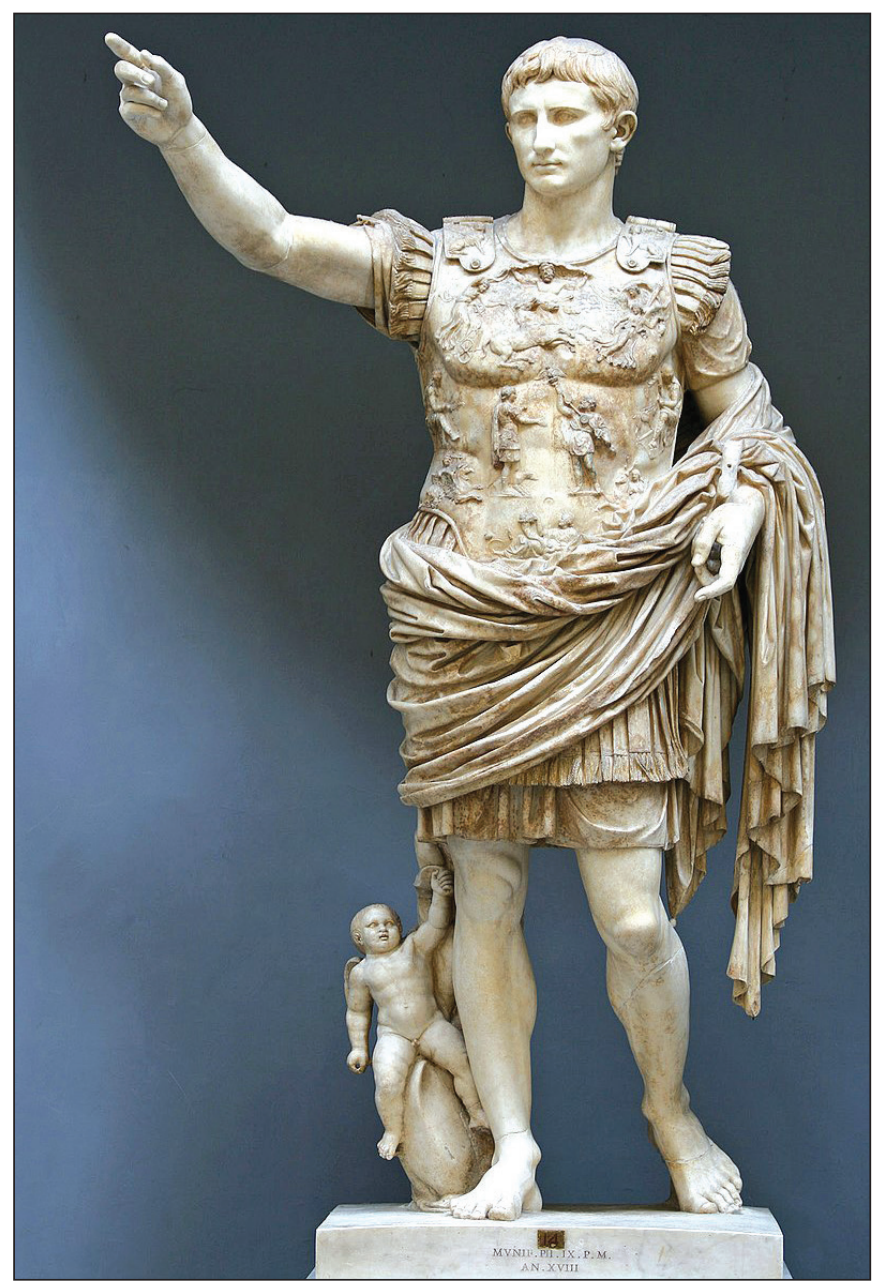

Figure 3: "Augustus of Prima Porta." Statue of Augustus Caesar. White marble, Vatican Museum, 1st century AD. Artist: Unknown https://en.wikipedia.org/wiki/Adlocutio (accessed August 7, 2018). 
The benediction sign appears when an individual attempts to make a fist, because the median nerve innervates motor branches to the flexors of the lower arm. Conversely, ulnar nerve pathology has been accepted as the anatomical cause of the benediction sign by some others $(1,2)$. The benediction sign can be seen when a patient attempts to extend all the fingers. Injury of the ulnar nerve impairs the lumbrical muscles and damages the ability to extend proximal and distal interphalangeal joints of the fourth and fifth digits.

The benediction sign mentioned in ancient literature is thought to be named after an early pope afflicted with Dupuytren's disease (12), or ulnar neuropathy (2). Futterman concluded that the functional anatomy involved in the making of an open hand is consistent with ulnar neuropathy (2). In considering cultural and historical norms, he studied images of many statues, paintings, icons, and photographs of the Papal lineage. According to him, an open hand was the standard hand position of greeting representing peaceful intentions to eliminate premediated violence and fear of hidden weapons.

Open handed figures were well-known symbols in pagan cultures of physitheism or the attribution of human physical traits to deities (17). In addition, tyrannical leaders such as Caesar and Hitler used an open hand edgesture to impress the public. The blessing gesture may be a result of ulnar neuropathy because as the index and long fingers show extension, the ring and small fingers would be left in a flexed position when a person attempted to open the hand (2).

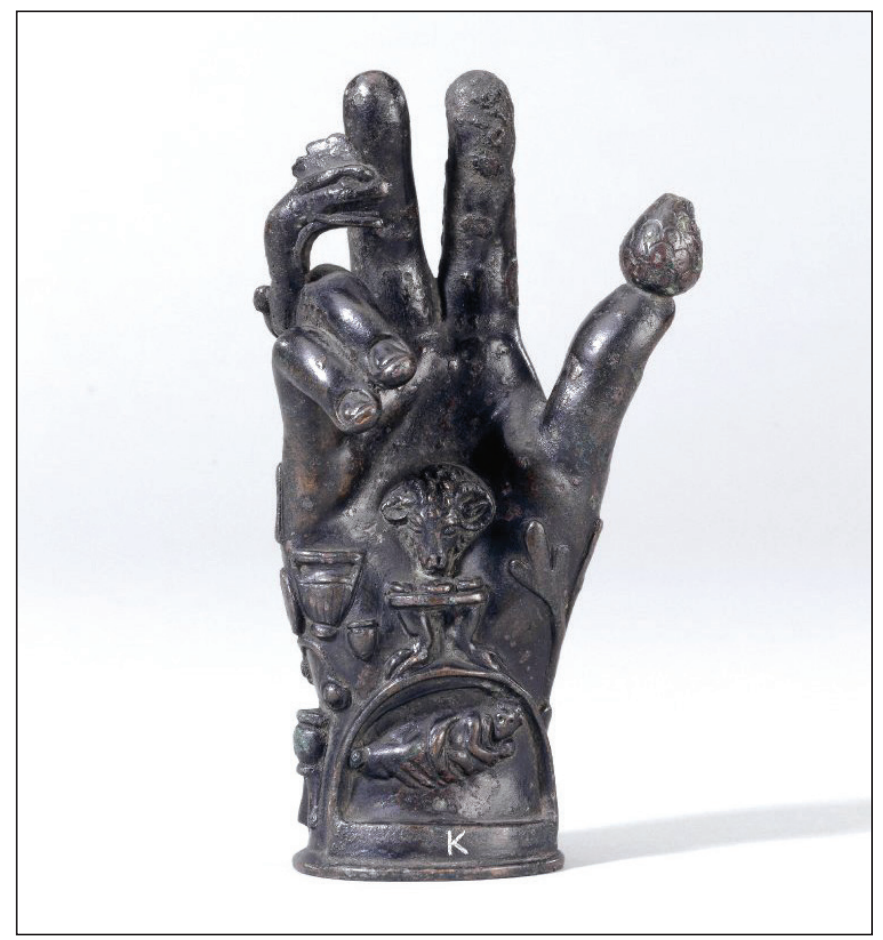

Figure 4: Bronze hand used in the worship of Sabazios (British Museum) https://www.britishmuseum.org/research/collection online/collection_object_details.aspx?objectld=463786\&partld=1 \&people $=94919 \&$ peoA $=94919-1-9 \&$ page $=1$ (accessed August 7 , 2018).
In his rigorous and detailed study, Zdilla suggested that the copper and bronzerelics called the "Hand of Sabazios" were evidence of Dupuytren's disease in antiquity, and the origin of the hand of benediction gesture (17) (Figure 4). Sabazios was a well-known god of fertility and vegetation among antique Greeks and Romans who populated the Italian and Anatolian peninsulas. The "Hand of Sabazios" relics with flexion of the fourth and fifth digits were likely used as religious icons (13).

Explanations of the benediction gesture in the previous paragraphs depend on chronic conditions such as Dupuytren's disease. Additionally, if there was a benediction gesture related to a gladiator combat, it could be because of an acute nerve injury. The gesture of mercy is a fist and the extension of the index finger. This suggests that the warrior could not form the gesture requesting mercy following a peripheral nerve injury during combat. While the index finger was could be extended, the other fingers could not flex in the strict sense of making a fist due to traumatic median nerve injury.

\section{CONCLUSION}

Artists are witnesses of history, not only of the period when they lived but of the social, cultural, and scientific accumulations of humanity that have been passed on to future generations. Artists are often inspired by events and models in the natural stream of life. Occurrences often could not be fully understood or were misunderstood because the context and documentation of witnessed scenes were not clear. The phenomenon of the mercy sign or gesture in the world of gladiators can be embodied in a different way in the eyes of an artist.

In the opinion of the author, the oil canvas "Pollice Verso" and the sculpture "Les Gladiateurs" represent a gladiator with an acute median nerve injury due to combat. Although the defeated warrior's intention was to extend his index finger while making a fist, his hand's action has remained in the position of the benediction sign. There is no way to know the thoughts of the artist in his depiction of these scenes. While he portrayed the hand of the gladiator, it was clear that the gesture was the benediction sign.

\section{REFERENCES}

1. Dutton $\mathrm{M}$ : Orthopaedic Examination, Evaluation and Intervention. 2nd ed. New York: McGraw-Hill, 2004: 557-559

2. Futterman B: Analysis of the papal benediction sign: The ulnar neuropathy of St. Peter. Clin Anat 28(6):696-701, 2015

3. Hering FF: Gérôme: The life and works of Jean Léon Gérôme. New York: Cassell Publishing Company, 1892: 88. https:// archive.org/details/grmelifeworksofj00heri (Accessed June 30, 2018)

4. https://en.wikipedia.org/wiki/Ave_Imperator,_morituri_te_ salutant(Accessed June 30, 2018)

5. https://www.artrenewal.org/Artwork/Index/290(Accessed June 30, 2018)

6. https://www.britannica.com/sports/gladiator (Accessed June $30,2018)$ 
7. https://www.britannica.com/biography/Jean-Leon-Gerome (Accessed June 30, 2018)

8. http://www.musee-orsay.fr/en/collections/index-of-works/ notice.html?no_cache $=1 \&$ nnumid $=005228 \& \mathrm{cHash}=7$ ec058b 61c(Accessed June 30, 2018)

9. http://penelope.uchicago.edu/ grout/encyclopaedia romana/gladiators/gladiators.html(Accessed June 30, 2018)

10. Jacobelli L: The spectacle from start to finish. In: Gladiators at Pompeii. Rome: L'Erma di Bretschneider, 2003: 25

11. Kanz F, Grossschmidt K: Head injuries of Roman gladiators. Forensic Sci Int 160(2-3):207-216,2006

12. Laha RK, Lunsford D, Dujovny M: Lacertus fibrousus compression of the median nerve. Case report. J Neurosurg 48(5): 838-841, 1978

13. Lowe D: Sabazius in the Aeneid (7.341-60). Vergilius 58:8191,2012
14. Mumenthaler $\mathrm{M}$, Mattle $\mathrm{H}$ : Peripheral nerve lesions. In: Mumenthaler M, Mattle H (eds), Fundamentals of Neurology. An Illustrated Guide. Wemding: Georg Thieme Verlag, 2006: 216-232

15. Smith W, Cheetham S: Benediction. In: A Dictionary of Christian Antiquities: Being a Continuation of the Dictionary of the Bible, vol: 1, London: John Murray, 1878:199. https:// books.google.com.tr/books? id=1LIPFk6oFVkC\&printsec=fro ntcover\&hl=tr\&source=gbs_ge_summary_r\&cad=0\#v=onepa ge\&q\&f=false(Accessed June 30, 2018)

16. Williams PL, Warwick R, Dyson M, Bannister L: The median nevre. In: Gray's anatomy. 37th ed. New York: Churchil Livingstone, 1989:1133-1137

17. Zdilla MJ: The hand of sabazios: Evidence of Dupuytren's disease in antiquity and the origin of the hand of benediction. J Hand Surg Asian Pac 22(3):403-410,2017 